\title{
The Preparation and Characterization of Ethanol Extract Nanoparticle from Rhaphidophora pinnata (L.f.) Schott Leaves by using Arabic Gum and Dextrin
}

\author{
Sumaiyah*, Masfria, Izmi Yolanda Rusdi, Aminah Dalimunthe \\ Faculty of Pharmacy, Universitas Sumatera Utara, Medan, INDONESIA.
}

\begin{abstract}
Objective: This research was aimed to prepare and characterize the ethanol extract nanoparticles of Rhaphidophora pinnata leaves by using arabic gum and dextrin. Method: The Rhaphidophora pinnata leaves extract was obtained via the percolation method using ethanol $96 \%$ and followed by evaporation process to form a thickened extract. The total water content and ash of the ethanol extract from Rhaphidophora pinnata leaves were determined. The ethanol extract of Rhaphidophora pinnata leaves was turned into nanoparticles by mixing the extract with arabic gum and dextrin. Then, it was sieved using a 20 mesh sieve. The resulting granules were dried in the oven at $40-45^{\circ} \mathrm{C}$. The dried granules were milled with ball milling equipment to obtain a powder in nanometer scale. The nanoparticle powder was then characterized using a Particle Size Analyzer to investigate its particle size and Scanning Electron Microscopy to determine the morphological conditions of the powder. Result: The nanoparticle powder was brown. The total water content and ash of the extract were $0.087 \%$ and $9.672 \%$, respectively. The characterization using PSA showed an average
\end{abstract}

particle size of $306.41 \mathrm{~nm}$. The SEM investigation showed that the particles morphology was uneven in surfaces, possesing irregular shapes, forming aggregates and not consistent in size. Conclusion: The nanoparticles of the ethanol extract from Rhaphidophora pinnata leaves have been prepared by using arabic gum and dextrin.

Key words: Arabic gum, Dextrin, Ethanol extract, Nanoparticles, Rhaphidophora pinnata.

\section{Correspondence}

Sumaiyah, Faculty of Pharmacy, Universitas Sumatera Utara, Tri Dharma Street, No. 5, University of Sumatera Utara Campus, Medan, INDONESIA, 20155.

Phone: +62 85361323060

Email: sumaiyah@usu.ac.id

DOI: 10.5530/jyp.2018.2s.16

\section{INTRODUCTION}

Currently, the research and development towards medicinal plants for both domestic and overseas has been rapidly developed, particularly in the field of drug efficacy and chemical analysis based on indication of medicinal plants that have been used by communities with empirical tested efficacy. The results of these studies ensure the users of medicinal plants regarding their efficacy and usefulness. ${ }^{1}$

According to the World Health Organization (WHO), the utilization of biodiversity is enormous. it is estimated that nearly $80 \%$ of human beings, especially in developing countries are still relying on plants (extracts and bioactive materials) as medicinal ingredients and to maintain health. The successful scientific research which revealed the efficacy, benefits of disease therapy, has encourage the emergence of a new paradigm in the world of modern medicine, which is "back to nature". ${ }^{2}$

One of the medicinal plants that is traditionally used by Indonesian people is Rhaphidophora pinnata (L.f.) Schott. This plant is a vines, has round stems, roots and hanging roots, and also has many uses. ${ }^{3}$ Rhaphidophora pinnataplantcontainsflavonoidcompounds, saponins, glycosides, steroids/ triterpenoids and polyhydroxy alkaloids. The polyhydroxy alkaloids content in Rhaphidophora pinnata leaves indicates its activity as an in vitro antimutagenic. ${ }^{4}$

The interest in nanotechnology research has been increased rapidly in the scientific field including drug delivery, nano-imaging, and other medical-related applications. Nanoparticles can be produced in many different shapes and sizes using organic and inorganic materials. However, by definition, these particles must be within the range of 1-1000 nm. Because the use of nanoparticles in drug delivery and nanomedicine is always required for parenteral delivering, and this has been and continues to be a major requirement for the use of both biocompatible and biodegradable polymer carriers. The applications of nanotechnology are to deliver therapeutic and diagnostic agents using biodegradable polymer nanoparticles for systemic, local and targeted delivery. ${ }^{5-6}$

In this research, arabic gum and dextrin were used to make nanoparticles-scale powder from extracts that can be served as a filler as well as a binder. Arabic gum can also be applied as a binder on food and drug substances. ${ }^{7-8}$ Moreover, arabic gum can be utilized as an emulsifier so that the ingredients that have been processed with the addition of arabic gum will be easily dissolved in water or oil. Meanwhile, dextrin that can be used as a material for encapsulating volatile compounds and oils, ${ }^{9}$ is stable against heat and oxidation in order to protect compounds against oxidation or heat. ${ }^{10}$

\section{MATERIALS AND METHODS}

Material

The materials used were Rhaphidophora pinnata leaves, ethanol 96\%, arabic gum, dextrin, and distilled water.

\section{Methods}

Rhaphidophora pinnata Leaves Extraction

The leaves of Rhaphidophora pinnata were dried using a drying hood. The dried Rhaphidophora pinnata leaves were mashed with a blender, then Rhaphidophora pinnata leaf powder was obtained. The powder was 
percolated with ethanol 96\%. After that, the obtained product was concentrated using a rotary evaporator to obtain a viscous ethanol extract of Rhaphidophora pinnata leaves.

\section{The Examination of Water Moisture and Total Ash Content from The Extract \\ Determination of Water Moisture Content}

As many as $5 \mathrm{~g}$ of extract was putted into a dry flask. Then, a $200 \mathrm{~mL}$ saturated toluene was inserted to the flask, the equipment was set. The saturated toluene was inserted to the flask through a cooler to the container. The flask was heated carefully for 15 minutes. After the boiling point of toluene was reached, the speed of distillation was adjusted to 2 drops per second until most of the water was distilled, and after that, the speed of distillation was adjusted to 4 drops per second. The distillation process was conducted for another 5 minutes. The receiving tube was cooled to reach room temperature. The volume of water can be determined after the water and toluene were completely separated. The water content was calculated in $\% \mathrm{v} / \mathrm{v}^{11}$

\section{Determination of Total Ash Content}

The extract was weighed for $2 \mathrm{~g}$ and inserted into a silicate crucible which was permitted at $600^{\circ} \mathrm{C}$ and had been towed. The extract was slowly permitted until the charcoal was removed, cooled and weighed. If the charcoal could not be removed, then, hot water was added, stirred, filtered through ash-free filter paper. Filter paper was permitted along with the rest of the filtering in the same crucible. The filtrate was inserted into crucible, evaporated and permitted to obtain a fixed weight. The total ash content was calculated against the weight of the test material, and expressed in $\% \mathrm{w} / \mathrm{w}^{11}$

\section{The Preparation of Ethanol Extract Nanoparticle from Rhaphidophora pinnata Leaves}

As many as $17.5 \mathrm{~g}$ of viscous extract, $12.33 \mathrm{~g}$ of arabic gum and $6.17 \mathrm{~g}$ of dextrin were weighed. All ingredients were mixed and crushed halfway. Then, it was sieved using a 20 mesh sieve and the resulting granules were dried in the oven at a temperature of $40-45^{\circ} \mathrm{C}$ and producing dried granules. The granules were crushed with a mortar to form a smaller particle, then turned into a nanoparticle-scale powder with ball milling method.

\section{The Characterization of Ethanol Extract Nanoparticle from Rhaphidophora pinnata Leaves}

The characterization of nanoparticles was performed by using Vasco ${ }^{\gamma}$ (Corduan) Technologies, France. Particle Size Analyzer (PSA) was utilized to measure the particle size and Scanning Electron Microscopy (SEM) Zeiss EVO MA 10 (Carl-Zeiss AG, Germany) was conducted to determine the powder morphological conditions. Before the analysis was conducted, the sample was coated with gold. The sample was placed on SEM microscope and observed.

\section{RESULTS}

\section{Water Moisture and Total Ash Content from The Extract}

The results of the examination of total water and ash content of simplicia and ethanolic extract of Rhaphidophora pinnata leaves can be seen in Table 1.

\section{Ethanol Extract Nanoparticle from Rhaphidophora pinnata Leaves}

The preparation of ethanol extract nanoparticle from Rhaphidophora pinnata leaves was done by using arabic gum and dextrin which can be used as filler material and as well as a binder. Figure 1 shows that the nanoparticles size distribution after treated with milling method. The ethanol extract nanoparticle from Rhaphidophora pinnata leaves produced was brown and the weight was approximately $20 \mathrm{~g}$.

The characterization using PSA showed the nanoparticle size distribution of Rhaphidophora pinnata leaves extract was in a nanometer range $(<1000 \mathrm{~nm})$, with an average size of $306.41 \mathrm{~nm}$. The PSA results are shown in Figure 2.

The characterization using SEM showed the morphological surface of particles is uneven, has irregular shape, forming aggregate, and not uniform in size (Figure 3).

\section{DISCUSSION}

The determination of water moisture content was performed to give maximum limit or range about the amount of water content. The allowed

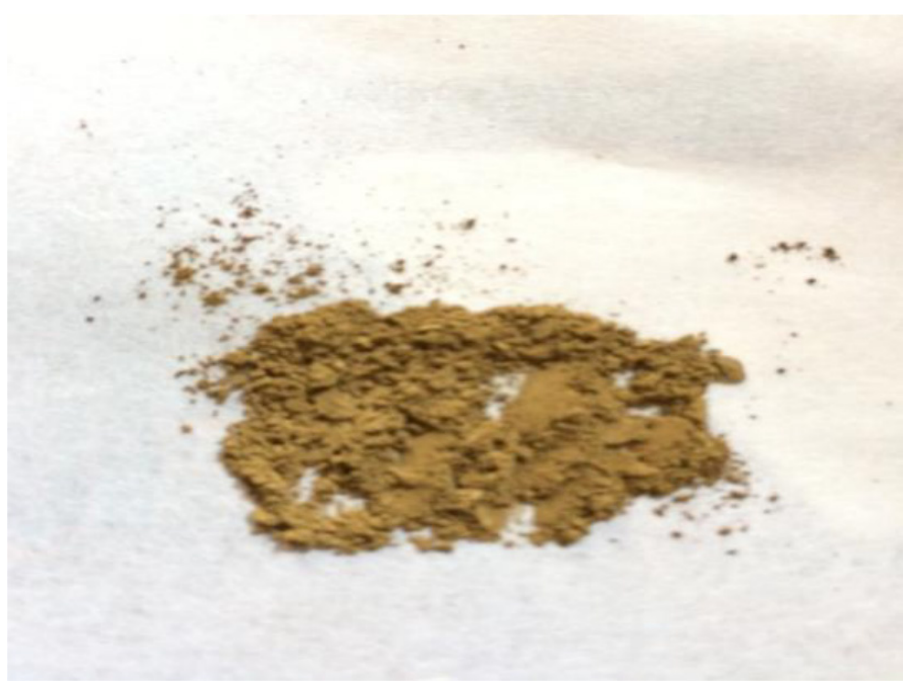

Figure 1: The ethanol extract powder from Rhaphidophora pinnata leaves.

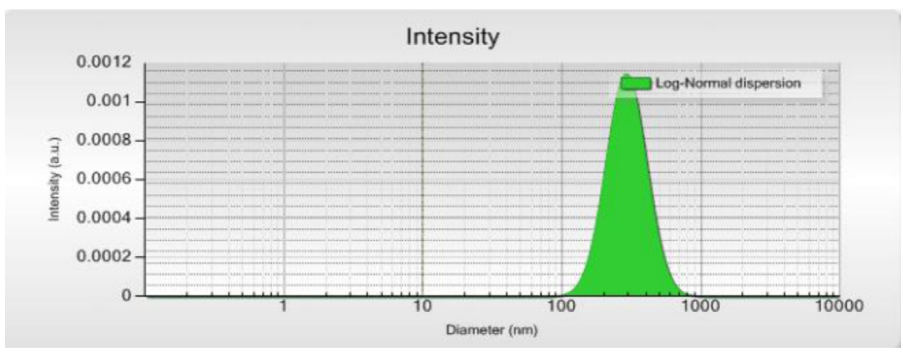

Figure 2: The result of particle size distribution measurement by using PSA.

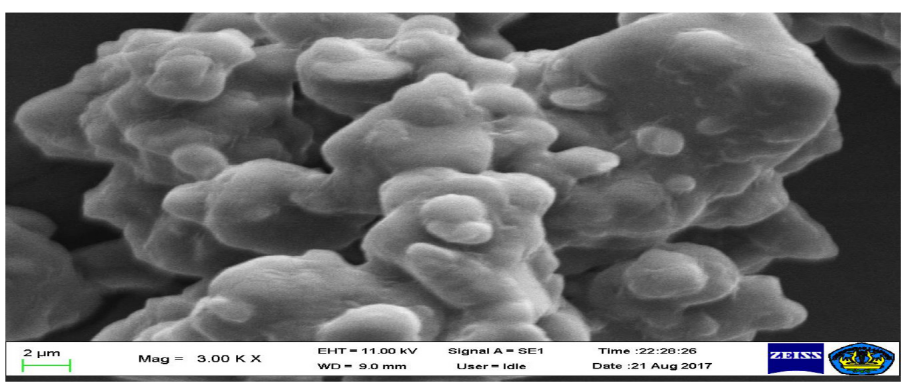

Figure 3: The result of SEM with 3000x magnification. 
Sumaiyah, et al.: The Preparation and Characterization of Ethanol Extract Nanoparticle from Rhaphidophora pinnata

Table 1: The water and total ash content of simplicia and ethanol extract from Rhaphidophora pinnata leaves

\begin{tabular}{cccc}
\hline No & Description & Result (\%) & \\
\hline & & Simplicia & Ethanol Extract \\
1 & Water content & 8.565 & 0.087 \\
2 & Total ash content & 8.670 & 9.672 \\
\hline
\end{tabular}

maximum value is related to purity and contamination. The method used was toluene distillation method. The result of the determination of water moisture content of extracts was $0.087 \%$, this is in accordance with the required water content which is $<10 \%$. The determination of total ash content was aimed to provide a description of mineral content derived from the initial process until the formation of extracts and to control the amount of contamination from inorganic objects. The method used was gravimetric method. It was found that the ash content was $9.672 \%$. The high value of total ash content indicated that the content of inorganic compounds were higher.

The preparation of ethanol extract nanoparticle from Rhaphidophora pinnata leaves was done by the top down method that change the big particles to be small particles in nanometer scale. The using of ball milling after ethanol extract of Rhaphidophora pinnata leaves crushed first in the mortar. To get particle of ethanol extract from Rhaphidophora pinnata leaves in nanoscale depended on the length of grinding time.

In the preparation of ethanol extract nanoparticle from Rhaphidophora pinnata leaves, arabic gum and dextrin which can be utilized as filler and binder were used to make a nanoparticle powder. Dextrin can be used as encapsulating agent of ethanol extract from Rhaphidophora pinnata leaves. ${ }^{12}$ In nanoparticle formulations, the percentage of binder (arabic gum: dextrin) concentration used has a ratio of $1: 0.5 ; 1: 1,75 ; 1: 3$; and 1:4.25 (data not shown). The best result obtained was a mixture of arabic gum and dextrin with a ratio of 1:0.5 which was easy to be granulated, dried, and milled to turn into nanoparticle powder. This is due to the ability of dextrin to strongly bind water. Dextrin is a polysaccharide that posseses a simpler chemical structure, consisted of 1,6 a-glucosidic and 1,4 a-glucosidic bonds. Dextrin is also easier to absorb water than arabic gum which has a more complex chemical structure, consisted of D-galactose, L-arabinose, D-glucuronic acid, and L-rhamnosa. ${ }^{13}$ In addition, dextrin that may be used as a material for encapsulating volatile compounds and oils, ${ }^{9}$ is stable against heat and oxidation process in order to protect the compound against oxidation or heat in the grinding process. ${ }^{10}$

Ethanol extract nanoparticle from Rhaphidophora pinnata leaves indicates its activity as an in vitro antimutagenic. The obtained nanoparticles of ethanol extract nanoparticle from Rhaphidophora pinnata leaves will be expected to give effect of antimutagenic in lower dose, it is due to the increasing of surface area and it will be easier to be exposed and lead to faster to release. ${ }^{14}$

\section{CONCLUSION}

Nanoparticles from the ethanol extract of Rhaphidophora pinnata leaves have been produced by using arabic gum and dextrin (1:0.5). The average size of the particles obtained was $887.01 \mathrm{~nm}$. SEM observations show that particle morphology has uneven surface, irregular shape, forming aggregate and not uniform in size.

\section{ACKNOWLEDGEMENT}

The authors would like to thank the Research Institute of the University of Sumatera Utara for the research funding support.

\section{CONFLICT OF INTEREST}

The authors declare no conflict of interest.

\section{ABBREVIATIONS}

SEM: Scanning electron microscopy; PSA: Particle size analyzer.

\section{SUMMARY}

Rhaphidophora pinnata plant contains flavonoid compounds, saponins, glycosides, steroid/ triterpenoids and polyhydroxy alkaloids. The polyhydroxy alkaloids content in Rhaphidophora pinnata leaves indicates its activity as an in vitro antimutagenic. Nanoparticles in drug delivery are to deliver therapeutic and diagnostic agents using biodegradable polymer nanoparticles for systemic, local and targeted delivery. In this study, nanoparticles from the ethanol extract of Rhaphidophora pinnata leaves have been produced by using arabic gum and dextrin (1:0.5). The average size of the particles obtained was $887.01 \mathrm{~nm}$. SEM observations show that particle morphology has uneven surface, irregular shape, forming aggregate and not uniform in size.

\section{REFERENCES}

1. Dalimarta S. Atlas Tumbuhan Obat Indonesia. Bogor: Trobus Agriwidya. 2000

2. Lemmens RH. Plant Resources Of South-East Asia. Leiden: Backhuys Publisher. 2003

3. Heyne K. Tumbuhan Berguna Indonesia. Jilid I. Cetakan I. Badan Litbang Kehutanan, Translator. Jakarta: Penerbit Yayasan Sarana Wanajaya. 1987;2:1188-9.

4. Masfria, Sumaiyah, Dalimunthe A. Antimutagenic Activity of Ethanol Extract of Rhaphidophora pinnata (Lf.) Schott Leaves on Mice. Scientia Pharmaceutica. 2017;85(7):1-4.

5. Chakkravarthi SS, Dennis HR. Biodegradabel Nanoparticles. In: Pharmaceutical Manufacturing Handbook Production and Process. Canada: John Wiley and Sons. 2008

6. Pradhan D, Tripathy G, Pradhan RK, Dasmohapatra T, Pradhan SP. A Review on Cuminosides Nanomedicine: Pharmacognostic Approach to Cancer Therapeutics. J Young Pharm. 2016;8(2):61-71.

7. Abdelgader $\mathrm{MO}$, Inaam Al. Application of Gum Arabic for coating of dried mango slices. Journal of Nutrition. 2011;10(5):457-62.

8. Sarkar S, Gupta S, Variyar PS, Sharma A, Singhal R. Irradiation depolymerized guar gum as partial replacement of gum Arabic for microencapsulation of mint oil. Carbohydrate Polymers. 2012;90(4):1685-94.

9. Aghbashlo M, Mobli H, Madadlou A, Rafiee S. The correlation of wall material composition with flow characteristics and encapsulation behavior of fish oil emulsion. Food Research International. 2012;49(1):379-88.

10. Abadio FD, Domingues AM, Borges SV, Oliveira VM. Physical properties of powdered pineapple (Ananas comosus) juice effect of malt dextrin concentration and atomization speed. Journal of Food Engineering. 2004;64(3):285-7.

11. Direktorat Jendral PO. Farmakope Herbal Indonesia. Edisi 1. Jakarta: Departemen Kesehatan RI. 2008

12. Goncalves C, Pereira P, Schellenberg P, Coutinbo PJ, Gama FM. Self-Assembled Dextrin Nanogel as Curcumin Delivery System. Journal of Biomaterials and Nanobiotechnology. 2012;3:178-84.

13. Hakim AR, Chamidah A. Application of Arabic Gum and Dextrin as Binder Protein of Shrimp Head Extract. JPB Kelautan dan Perikanan. 2013;8(1):45-54.

14. Pal SL, Jana U, Manna PK, Mohanta GP, Manavalan R. Nanoparticle: An Overview of Preparation and Characterization. Journal of Applied Pharmaceutical Science. $2011 ; 1(06): 228-34$ 